- Patients with previous knee surgery, recent trauma, or intraarticular intervention. - Patients with knee effusion, active synovitis, or popliteal cysts.

All patients were subjected to ultrasound assessment in gray scale and Power Doppler was performed using a scanner with a multifrequency $12 \mathrm{~L}$ linear array transducer (General electric Systems; LOGIQU-E). Ultrasound techniques were used for all patients included in the study. Knee was assessed for the following items in both sides while Patient lying supine with the knee flexed 40 degrees: 1) Superior pole of the patella - quadriceps tendon enthesis: • Quadriceps tendon thickness $>6.1 \mathrm{~mm}$ - Suprapatellar bursitis - Superior pole of patella erosion • Superior pole of patella enthesophyte.

2) Inferior pole of the patella - proximal patellar ligament enthesis: - Patellar ligament thickness $>4 \mathrm{~mm}$ - Inferior pole of patella erosion - Inferior pole of patella enthesophyte.

3) Tibial tuberosity - distal patellar ligament enthesis • Patellar ligament thickness $>4 \mathrm{~mm}$ - Infrapatellar bursitis - Tibial tuberosity erosion • Tibial tuberosity enthesophyte.

Knee functional status was assessed using KOOS scale for Pain, other Symptoms, Activities of Daily Living (ADL), Sport and Recreation Function (Sport/Rec) and knee-related Quality of Life (QOL). Low knee function was considered if the patient had score 50 or more in any KOOS scale parameter.

Results: 172 (42\%) patients were found with low knee function among them quadriceps enthesitis found in $114(66.3 \%)$ patients, at the patellar attachment of infrapatellar ligament in 160 (93\%) patients, and enthesitis at the tibial attachment of infrapatellar ligament in $44(26 \%)$ patients. Good knee function were found in $238(58 \%)$ patients among them quadriceps enthesitis found in $76(31.9 \%)$ patients, at the patellar attachment of infrapatellar ligament in $87(36.3 \%)$ patients, and no enthesitis at the tibial attachment of infrapatellar ligament were detected. Conclusions: Enthesitis at the quadriceps and infrapatellar ligament represent a common ultrasonographic finding in patients with longstanding $\mathrm{KOA}$, and significantly associated with low knee function.

Disclosure of Interest: None declared

DOI: 10.1136/annrheumdis-2017-eular.4284

\section{SAT0496 SAFETY OF DIACEREIN IN PATIENTS WITH OSTEOARTHRITIS - A REAL WORLD EXPERIENCE WITH UNEXPECTED RESULTS}

A. Malpica ${ }^{1}$, K. Mendez ${ }^{2}$, P. Santos-Moreno ${ }^{3,3,3}$, L. Villarreal $^{4}$,

D. Buitrago-Garcia ${ }^{1}$. ${ }^{1}$ Epidemiology; ${ }^{2}$ Pharmaceutical chemist; ${ }^{3}$ Rheumatology;

${ }^{4}$ Psychology and processes, Biomab, Center for Rheumatoid Arthritis, Bogota,

Bogota, Colombia

Background: Osteoarthritis $(\mathrm{OA})$ is a common joint disorder and may occur in any synovial joint in the body, the condition is common in hands, knees, hips and spine. Diacerein is a antraquinone derivate has shown the inhibition of cytokine interleukine 1-B (1). A Cochrane review published in in 2014 showed that diacerein could be effective for this condition, however the most frequent adverse event with this medication was diarrhea compared to placebo RR $3.52(95 \% \mathrm{Cl}$ 2.42 to 5.11$)$ or other symptomatic slow acting drugs for OA $3.20(95 \% \mathrm{Cl} 1.58$ to 6.49) (2).

Objectives: To describe the real-world safety of Diacerein in patients with $O A$ in a specialized center in Bogotá, Colombia.

Methods: We performed a cross-sectional study; patients with confirmed criteria of osteoarthritis and treated on a regularly basis with Diacerein were included. Patients were followed during a 18 month period. Adverse events were classified according the Common Terminology Criteria for Adverse Events (CTCAE) of the World Health Organization. Descriptive epidemiology for continuous variables, measure of central tendency and dispersion for qualitative and categorical variables through percentages and averages were calculated, we analyzed bi-variated correlations with $\mathrm{X} 2$ test.

Results: 1278 patients meet inclusion criteria; mean age was 62 year \pm 10 years. $88 \%$ were female and $12 \%$ male, due to our patient's condition $80 \%$ of them were polimedicated. $93 \%$ of our patients received diacerein in usual dose of $100 \mathrm{mg}$ daily and remaining $7 \%$ in a $50 \mathrm{mg}$ day dose. Regarding safety $7.5 \%(\mathrm{n}=96)$ of our patients reported any event adverse, the most frequent event was diarrhea with $50 \%$, followed by nausea and abdominal disturbances among others. According to the CTAE classification the events adverse were mild $98 \%$ and only $2 \%$ severe; that means only $0.075 \%$ of total of patients receiving Diacerein had severe AE. On the other hand, correlation between adverse events and polymedication were statistical significant $(P=0.000)$. For this reason we consider that $A E$ such as diarrhea can be attributed more to patients' polymedication than diacerein.

Conclusions: This evidence showed a low proportion of patients with adverse events taking Diacerein; also most of these patients were polymedicated giving as a result a higher risk of having an adverse event. When we compared our results to other studies diarrhea was the most frequent event, followed by nausea, but only a very low proportion of patients were forced to discontinue medication. It is important to continue following patients that take diacerein in order to report its true safety and effectiveness.

References:

[1] Bartels EM, Bliddal H, Schondorff PK, Altman RD, Zhang W, Christensen R. Symptomatic efficacy and safety of diacerein in the treatment of osteoarthritis: a meta-analysis of randomized placebo-controlled trials. Osteoarthritis and cartilage. 2010;18(3):289-96.
[2] Fidelix TS, Macedo CR, Maxwell LJ, Fernandes Moca Trevisani V. Diacerein for osteoarthritis. The Cochrane database of systematic reviews. 2014(2):Cd005117.

Disclosure of Interest: None declared

DOI: 10.1136/annrheumdis-2017-eular.5272

\section{SAT0497 WHAT ARE THE PATIENTS' EXPERIENCE, NEEDS AND EXPECTATIONS IN HAND OSTEOARTHRITIS? A QUALITATIVE EVALUATION}

M.-A. Offroy, A. Frazier-Mironer. Centre Viggo Petersen, Rheumatology Department, APHP Lariboisière Hospital, Paris, France

Background: The objective of this study was to evaluate the patients' experience and needs with $\mathrm{HOA}$, in order to establish a therapeutic education program for HOA patients.

Objectives: As the subject was about descriptive, not quantifiable elements, qualitative methodology was chosen. Patients were submitted to individual semidirective interviews. Verbatim were analyzed following the grounded theory until saturation of data.

Methods: Twelve HOA patients accepted to participate to the study. There were 10 women and 2 men, aged 45 to 79 years. Body-mass indexes varied from 18.7 to $31.6 \mathrm{~kg} / \mathrm{m}^{2}$. Clinical and radiological severity of HOA varied among patients. They provided data on the experience of HOA, which is influenced by clinical and functional signs and the evolution of the disease. Pain and deformity are the main clinical signs, and lead to severe functional impairment. The functional, psychological, social consequences of $\mathrm{HOA}$ also have an impact on the patient experience. Patients develop adaptive strategies, mainly recourse to medical management, and pharmacological and non-pharmacological therapies. The needs of HOA patients were also explored, and three main ideas emerged. First, they want to be better informed on HOA. Second, they have a feeling of failure of conventional medicine, and often use alternative medicines. Third, the fear of disability with the course of the disease is very strong. They have difficulty accepting pharmacological treatments, but often do not realize the therapeutic nature of non-pharmacological treatments.

Results: The main concerns of HOA patients are: information, nonpharmacological treatments and evolutionary risks. These themes should be included in the development of therapeutic education programs for HOA.

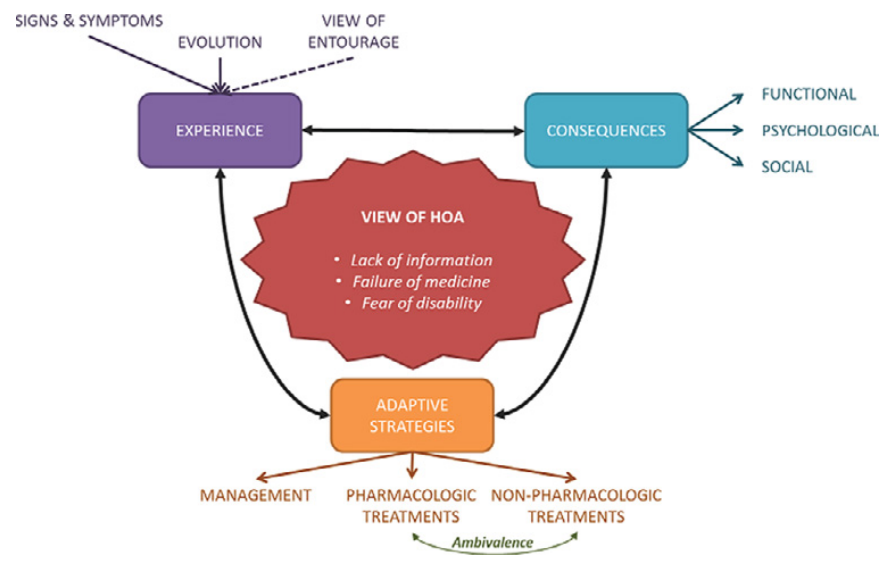

References:

[1] We thank Pr François Rannou, Pr Pascal Richette and Pr Eric Roulot for providing access to HOA consultation in their centers for recruitment. We thank Dr Laurence Baumann-Coblenz for her advice in qualitative methodology.

Acknowledgements: We thank Pr François Rannou, Pr Pascal Richette and Pr Eric Roulot for providing access to HOA consultation in their centers for recruitment. We thank Dr Laurence Baumann-Coblenz for her advice in qualitative methodology.

Disclosure of Interest: None declared

DOI: 10.1136/annrheumdis-2017-eular.1203

\section{SAT0498 THE PERFORMANCE OF URINARY COLLAGEN TYPE II C-TELOPEPTIDE (UCTX-II) IN KNEE OSTEOARTHRITIS: A META-ANALYSIS}

B. Jeremiasse, F.P. Lafeber, W.E. Van Spil. Department of Rheumatology and Clinical Immunology, UMC Utrecht, Utrecht, Netherlands

Background: Among the currently available biochemical markers for osteoarthritis (OA), urinary collagen type II C-telopeptide (UCTX-II) is one of the most frequently investigated markers ${ }^{1}$. Much research has been performed into the performance of UCTX-II, but most of it in relatively small cohort studies ${ }^{1}$. Therefore, we performed a meta-analysis to summarize UCTX-II studies in a quantitative way. Objectives: To perform a meta-analysis of the performance of UCTX-II as a biomarker for diagnosing knee osteoarthritis (KOA) and its association with radio- 